\title{
Consensus statements on diagnosis and management of chronic idiopathic constipation in adults in Hong Kong
}

\author{
Justin CY Wu *, Annie 00 Chan, TK Cheung, Ambrose CP Kwan, Vincent KS Leung, WC Sze, \\ Victoria PY Tan
}

\section{A B S T R A C T}

Objective: The estimated prevalence of chronic idiopathic constipation in Hong Kong is $14 \%$. An expert panel of local gastroenterologists has created a set of consensus statements with the aim of providing localised guidance on the diagnosis and management of this common condition by primary care physicians.

Participants: An expert panel consisting of seven local gastroenterologists convened in August 2018 in Hong Kong.

Evidence: Published primary research articles, metaanalyses, and guidelines and consensus statements issued by different regional and international societies on the diagnosis and management of chronic idiopathic constipation were reviewed.

Consensus process: Draft consensus statements were prepared prior to the meeting. The consensus statements were finalised during the meeting with contributions from the panel members based on their collective knowledge and clinical experience.

Conclusions: A total of 11 consensus statements were created, including five concerning patient assessment and diagnosis, two relating to nonpharmacological management, and four on pharmacological management. These consensus statements are intended to provide guidance to local general practitioners and primary care physicians on managing patients with chronic constipation in daily clinical practice.

\section{Hong Kong Med J 2019;25:142-8}

https://doi.org/10.12809/hkmj187692

\footnotetext{
${ }^{1} \mathrm{JCY}$ Wu *, MB, ChB, MD

${ }^{2} \mathrm{AOO}$ Chan, MB, ChB, PhD

${ }^{3}$ TK Cheung, MB, BS, PhD

${ }^{3}$ ACP Kwan, MB, BS

${ }^{4}$ VKS Leung, MB, BS

${ }^{3}$ WC Sze, MB, BS, GradDFM

${ }^{5}$ VPY Tan, MB, BS
}

${ }^{1}$ Department of Medicine and Therapeutics, The Chinese University of Hong Kong, Shatin, Hong Kong

2 Department of Gastroenterology and Hepatology, Hong Kong

Sanatorium \& Hospital, Happy Valley, Hong Kong

${ }^{3}$ Private Practice, Hong Kong

${ }^{4}$ Department of Gastroenterology and Hepatology, Hong Kong Baptist

Hospital, Kowloon Tong, Hong Kong

${ }^{5}$ Department of Medicine, The University of Hong Kong, Pokfulam, Hong Kong

* Corresponding author: justinwu@cuhk.edu.hk

\section{Introduction}

Chronic idiopathic constipation (CIC), also known as functional constipation, is a common gastrointestinal disorder with an estimated prevalence of $14 \%$ in the Hong Kong general population. ${ }^{1}$ Constipation is often perceived as a decrease in frequency of bowel movements, but normal bowel function can range anywhere from 3 times daily to 3 times weekly, and fewer than $50 \%$ of people experience the conventional norm of once-daily bowel motion. ${ }^{2}$ In addition to infrequent bowel movements, patients with chronic constipation also complain of straining, hard stools, abdominal discomfort, and feelings of incomplete evacuation. ${ }^{3}$ In the primary care setting, the Rome IV criteria may guide diagnosis of $\mathrm{CIC}$, along with simple laboratory tests and physical examination to rule out secondary causes. ${ }^{4,5}$

Management of CIC typically begins with nonpharmacological measures including exercise and increased dietary fibre and fluid intake. When these general measures have failed to relieve constipation, therapies, such as bulking agents, osmotic laxatives, stimulant laxatives, and stool softeners are used to promote regular bowel movements. Newer pharmacological therapies include prokinetic agents (5- $\mathrm{HT}_{4}$ agonists) that promote gut motility and prosecretory agents (guanylate cyclase $\mathrm{C}$ agonists) that increase intestinal secretion. In Hong Kong, patients also seek Chinese herbal medicine and acupuncture for relief of constipation.

Current management practices for CIC in Hong Kong largely follow Western guidelines and principles. Given that there are cultural differences among patients and physicians regarding symptom perception, treatment practices, and goals, there is a need for localised CIC management guidelines. Hence, these consensus statements were developed with the aim of providing guidance to local primary 
care physicians on diagnosis and management of CIC.

\section{Methods}

An expert panel consisting of seven local gastroenterologists convened on 9 August 2018 in Hong Kong. Published primary research articles, meta-analyses, and guidelines and consensus statements issued by different regional and international societies on CIC diagnosis and management were reviewed, and draft consensus statements were prepared prior to the meeting. These statements were divided into three sections: patient assessment and diagnosis, non-pharmacological management, and pharmacological management. The consensus statements were finalised during the meeting with contributions from the panel members based on their collective knowledge and clinical experience.

\section{Results}

\section{Patient assessment and diagnosis}

Statement 1: Primary care doctors are the major care providers for diagnosis and management of chronic idiopathic constipation

The Rome IV diagnostic criteria for CIC can be too complex and impractical for daily use in the primary care setting. Adopting a pragmatic approach that combines these symptom criteria with other elements, such as a visual guide (Bristol Stool Scale) and quality of life impairment, may enhance diagnosis of constipation and evaluation of its severity. Higher vigilance about the patient's regular use of natural products or health supplements to promote bowel function is also important, as it is often overlooked.

Patients with symptoms that are refractory to second-line treatment should be referred for specialist assessment. Failure to fulfil diagnostic criteria should not preclude referral to a gastroenterologist, especially in patients with complications or bothersome symptoms that affect their quality of life. Patients with alarming features, such as anaemia, recent onset of symptoms after 50 years of their absence, rectal bleeding, significant weight loss, abnormal physical examination, and family history of colon cancer should also be referred for further assessment. ${ }^{4-6}$ Psychiatric comorbidities are not uncommon in patients with chronic constipation, and any feature of significant psychiatric co-morbidities should prompt referral to a psychiatrist. ${ }^{7}$

Statement 2: Routine extensive diagnostic and physiological testing is not recommended for chronic constipation

Thorough history taking pertaining to age

\section{關於診斷和治理香港成年人慢性自發性便秘的 共識聲明}

胡志遠、陳安安、張鼎堅、關治邦、梁景冧、施緢知、陳萍兒

目的：香港慢性自發性便秘的現患率估計約 $14 \%$ 。本地胃腸科專家小 組已制定了一套共識聲明, 旨在為初級保健醫生診斷和治理這種常見 病症提供本地指引

參與者：由7名本地胃腸科醫生組成的專家小組於 2018 年8月在香港召 開會議。

證據：審查不同地區及國際組織發佈有關慢性自發性便秘診斷和治理 的主要研究論文、著萃分析、指南及共識聲明。

共識過程 : 會議前預備共識聲明草案。會議期間根據小組成員的集體 知識和臨床經驗, 最終確定共識聲明。

結論：共創建 11 項共識聲明，其中5項涉及患者評估和診斷、2項涉及 非藥物治理, 及4項涉及藥理學治理。這些共識聲明旨在為本地全科 醫生和初級保健醫生提供日常臨床實踐中治理慢性便秘患者的指引。 symptomology, acuteness of symptoms, and medication history is important to exclude various causes of constipation. ${ }^{5,8}$ Preliminary laboratory investigations consisting of complete blood count, serum calcium, glucose levels, and thyroid function tests are generally adequate to screen for underlying metabolic or other organic pathology. ${ }^{5,8,9}$ Careful abdominal and digital rectal examinations are also important in the primary care setting. A rectal exam can reveal rectal tumours, haemorrhoids, impacted faeces, anal sphincter tone, presence of mucus, and stool colour. ${ }^{5,8,9}$ Abdominal X-ray is a simple, non-invasive investigation that may show faecal impaction. These investigations have to be individualised according to patient expectations and preferences.

Advanced diagnostic procedures, such as barium enema, defaecography, colonic transit studies, magnetic resonance imaging, manometry, and balloon expulsion test should be reserved for patients with suspected slow transit constipation and defaecatory disorder in the specialist care setting.

Statement 3: Differential diagnoses of chronic idiopathic constipation include secondary causes of constipation, such as medications, electrolyte imbalances, structural abnormalities and metabolic (eg, hypothyroidism, hypercalcaemia, diabetes mellitus) or pathological (eg, Parkinson's disease, multiple sclerosis) disorders. Alarming features suggestive of a serious gastrointestinal disorder should prompt referral to a gastroenterologist or surgeon

Constipation is a common adverse reaction to many medications (notably opioids, diuretics, 
antidepressants, antihistamines, antispasmodics, anticonvulsants, aluminium antacids, and iron supplements), and constipation may necessitate their discontinuation, if appropriate. ${ }^{8,10}$ Intake of herbal supplements and traditional Chinese medicines should also be considered as potential causes.

Any recent onset of constipation with alarming symptoms should prompt the need for exclusion of colorectal cancer. Although there is no evidence for an association between chronic constipation and increased colorectal cancer risk, colon cancer screening may be warranted in individuals $>50$ years with recent onset constipation and/or other alarming features. ${ }^{5,11}$

\section{Statement 4: The revised Rome IV criteria are useful for diagnosing chronic idiopathic constipation but can be cumbersome to use in clinical practice}

The Rome IV criteria define CIC as the presence of two or more of the following 5 :

- Straining during more than $25 \%$ of defaecations;

- Lumpy or hard stools in more than $25 \%$ of defaecations;

- Sensation of incomplete evacuation in more than $25 \%$ of defaecations;

- Sensation of anorectal obstruction/blockage in more than $25 \%$ of defaecations;

- Manual manoeuvres to facilitate more than 25\% of defaecations (eg, digital evacuation, support of the pelvic floor);

- Fewer than three defaecations per week.

Loose stools should rarely be present without the use of laxatives, and there should be insufficient criteria for irritable bowel syndrome. These criteria need to be fulfilled for the last 3 months with symptom onset at least 6 months prior to diagnosis.

It is important to recognise that there is a significant overlap between CIC and constipationpredominant irritable bowel syndrome. Both conditions exist on a continuous spectrum, but the latter is distinguished by the presence of abdominal pain. ${ }^{5}$ Patients with CIC may periodically encounter symptoms of constipation related to irritable bowel syndrome.

The long duration required after symptom onset is a major limitation of the Rome IV criteria. Instead, cases with recurrent presentation to the clinic with consistent symptoms should be considered for diagnosis of CIC. The chronic constipation diagnostic tool proposed by the Asian Neurogastroenterology and Motility Association, which requires a duration of only 3 months after symptom onset for diagnosis, has been demonstrated as a useful alternative to the Rome III criteria in Asian patients. ${ }^{12}$

The Bristol Stool Scale is a useful guide for facilitating communication with patients, although it may not include the subset of patients who present with difficulty passing stool but do not have type 1 or 2 stool consistency. Patients should also be encouraged to keep a stool diary and record their bowel habits to facilitate accurate diagnosis., ${ }^{40}$

Statement 5: Chronic constipation can be classified as normal-transit, slow-transit, or defaecatory disorder

This pathophysiological classification categorises constipation according to colonic transit time and additional functional or anatomical disruption that leads to obstructed defaecation. It is made with the aid of advanced tests performed by gastroenterologists but should not significantly affect first-line management in the primary care setting. These pathophysiological mechanisms may co-exist and contribute to treatment refractoriness in some patients. In each of these categories, there may be underlying secondary causes that need careful evaluation. For example, slow transit constipation can be a gastrointestinal manifestation commonly seen in patients with Parkinson's disease. Slow transit constipation is strongly associated with irritable bowel syndrome. Anorectal structural pathology, such as rectocele, may contribute to defaecatory disorder.

Rectal hyposensitivity has been proposed as a mechanism associated with constipation, but it is generally believed to be a consequence of $\mathrm{CIC}$, resulting from chronic rectal distension, rather than a cause. ${ }^{13}$

\section{Non-pharmacological management}

Statement 6: Dietary and lifestyle adjustments, including a high-fibre diet, adequate hydration, and physical activity, should be made before starting pharmacological treatment. Patients with pelvic floor dysfunction should be referred for physiotherapy

In recent years, the Hong Kong Chinese diet has become increasingly low in dietary fibre. The dietary fibre intake of the Hong Kong Chinese population is estimated to be only 10 to $12 \mathrm{~g} / \mathrm{day}-$ barely half of that seen in Western societies (about 20 g/day). ${ }^{14}$ Although some patients may benefit from a fibre-rich diet, there are currently no data showing that increasing dietary fibre will help to relieve constipation. ${ }^{8,15}$ Furthermore, excessive fibre intake may actually worsen symptoms in severely constipated patients. ${ }^{15}$ Particularly, elderly patients and those with inadequate fluid intake or on diuretics may be at risk. ${ }^{8}$ Hence, a high-fibre diet should be accompanied by adequate hydration to avoid symptoms of faecal impaction. Consumption of fruits high in soluble fibre, including papayas and kiwis, can be recommended to patients.

Dysbiosis has been associated with 
constipation in some studies. However, there is insufficient evidence to recommend probiotics as an effective remedy for $\mathrm{CIC}$. $^{8,10,16}$

Developing good toilet habits can be beneficial. Patients should be encouraged to schedule routine bathroom time (postprandial, when urge may be higher) and use simple manoeuvres, such as elevating the feet with a footstool. ${ }^{5}$ Prolonged sitting ( $>10$ minutes) on the toilet is not recommended.

\section{Statement 7: Data on the use of traditional} Chinese medicine in the management of chronic idiopathic constipation are conflicting

A 16-week randomised double-blind clinical trial conducted in Hong Kong on 291 patients with CIC showed that the hemp seed-containing Chinese herbal formula, MaZiRenWan, was significantly more effective than placebo at increasing the number of complete spontaneous bowel movements (CSBMs; $\mathrm{P}<0.005$ at week 8 and week 16) but not more effective than the stimulant laxative senna $(\mathrm{P}=0.14$ at week 8). ${ }^{17-19}$ Patients should be asked about their use of Chinese medicine, as is commonly used for constipation. It may substantiate the effectiveness of the treatment or contribute to adverse effects.

\section{Pharmacological management}

Statement 8: Pharmacological management should be considered if lifestyle and dietary measures do not provide adequate relief of chronic idiopathic constipation. First-line pharmacological treatments recommended in primary care include bulking agents, osmotic laxatives, and stool softeners. Combination therapy with agents across different classes/ mechanisms can be considered before moving to second-line therapy

Commonly used bulk-forming agents include soluble fibre, such as psyllium, methylcellulose, and polycarbophil and insoluble fibre, such as wheat bran. A meta-analysis of three randomised controlled trials involving 293 patients with CIC showed that soluble fibre supplementation increases stool frequency (relative risk $[R R]=0.25 ; 95 \%$ confidence interval $[\mathrm{CI}]=0.16-0.37) .{ }^{16}$ Long-term use of bulking agents, especially insoluble fibre, is discouraged because of their propensity to cause bloating and discomfort. ${ }^{16}$ Caution should be exercised when giving bulk-forming agents to patients already on a high-fibre diet, as this may worsen faecal impaction.

Electrolyte-free polyethylene glycol (PEG) and lactulose are commonly recommended osmotic laxatives in CIC. A meta-analysis of 10 randomised controlled trials concluded that PEG was superior to lactulose in outcomes of stool frequency, consistency, and relief of abdominal pain. ${ }^{19}$ In general, PEG is also better tolerated (less likely to cause bloating and gas) than lactulose, which may result in better compliance by patients. ${ }^{6}$ Given the favourable efficacy and safety profile, long-term use of PEG is acceptable as a first-line treatment for $\mathrm{CIC}{ }^{8}$ The use of phosphate solution is strongly discouraged because of the high potential for serious complications, including phosphate nephropathy and electrolyte imbalances, especially in elderly people..$^{5,20,21}$ The panel does not recommend the stool softener docusate as a primary treatment for CIC given that it was shown to be inferior to psyllium at improving stool frequency in a randomised controlled trial involving 170 patients with $\mathrm{CIC}{ }^{22}$

Patients require adequate counselling on regular, consistent use of medications, regardless of clinical status after dose titration, to prevent the development of severe refractory symptoms.

Treatment goals should be realistic. Various outcome measures and definitions of treatment response have been reported in clinical trials on constipation. In general, achieving one additional spontaneous bowel movement per week from baseline is recommended as an indicator of initial positive response. Patients should be counselled that the normal bowel frequency is a minimum of 3 times per week rather than once daily. In addition to achieving the desired bowel frequency, a successful treatment response should also encompass improvement in quality of life and prevention of complications.

Treatment failure can be considered after 2 months (alongside non-pharmacological measures) before proceeding to second-line therapy. ${ }^{6}$ This period is also dependent on patient preference.

Statement 9: Linaclotide can be considered as second-line treatment for chronic idiopathic constipation. Diarrhoea may be an adverse effect in some patients, and patients should be educated about this possibility before initiating therapy. Careful vigilance for severe diarrhoea is recommended before long-term regular use

Second-line pharmacotherapeutic options for CIC include prokinetic agents (prucalopride) and prosecretory agents (lubiprostone, linaclotide, plecanatide). ${ }^{6,23}$ Both linaclotide and lubiprostone have shown high-quality evidence of efficacy and safety for treatment of CIC. ${ }^{16}$ Currently, linaclotide $(290 \mu \mathrm{g})$ is the only agent in this category that is registered for use in Hong Kong. Because the general recommended daily dose of linaclotide for CIC is 145 $\mu \mathrm{g}$, once-every-2-days dosing of the 290- $\mu \mathrm{g}$ capsule is recommended to minimise diarrhoea and improve tolerability. ${ }^{5,6}$

Four randomised clinical trials involving 651 patients demonstrated that lubiprostone was superior to placebo for treatment of CIC $(R R=0.67$; 95\% CI=0.58-0.77). ${ }^{16}$ Diarrhoea and nausea occurred 
significantly more frequently with lubiprostone. ${ }^{16}$

The efficacy and safety of linaclotide were evaluated in two 12-week randomised doubleblind placebo-controlled dual-dose (145 $\mu \mathrm{g}$ and $290 \mu \mathrm{g})$ trials involving 1276 patients with chronic constipation. In both trials, a significantly higher proportion of patients receiving linaclotide achieved the primary endpoint ( $\geq 3$ CSBMs per week and an increase of $\geq 1$ CSBMs from baseline during at least 9 of the 12 weeks) compared with those receiving placebo $\left(\mathrm{P}<0.01\right.$ for all comparisons) ${ }^{24}$ In addition, linaclotide significantly improved stool frequency and consistency, reduced straining, and reduced abdominal symptoms (bloating and discomfort). A meta-analysis that combined these two trials and a previous phase II dose-ranging trial conducted in 310 patients with $\mathrm{CIC}$ reported that $79 \%$ of those receiving linaclotide failed to respond to therapy, as compared with $94.9 \%$ of placebo-treated patients ( $\mathrm{RR}=0.84 ; 95 \% \mathrm{CI}=0.80-0.87$ ), and diarrhoea was more common with linaclotide treatment $(\mathrm{RR}=3.08$; 95\% $\mathrm{CI}=1.27-7.48) .{ }^{25}$ In a subsequent phase IIIb trial conducted in 483 patients with chronic constipation and significant abdominal bloating, linaclotide significantly improved bowel symptoms and bloating compared with placebo. ${ }^{26}$

Two large randomised placebo-controlled trials $(n=2731)$ have recently demonstrated the efficacy of plecanatide (3-mg and 6-mg doses) at improving CIC. ${ }^{27,28}$ Both trials reported a significant improvement in the proportion of durable CSBM responders and a small incidence of diarrhoea. ${ }^{27,28}$

Because prosecretory agents induce active secretion of electrolytes and fluids into the intestinal lumen, monitoring baseline renal function is advisable in selected patients who are at risk of

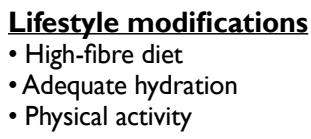

First-line pharmacological management
Bulking agents
- Psyllium
- Methylcellulose
- Polycarbophil
Osmotic laxative
- Polyethylene glycol

- Polyethylene glycol

\section{Second-line pharmacological management} Prosecretory agents

- Linaclotide

FIG. Management algorithm for chronic idiopathic constipation in Hong Kong (based on expert review of the current evidence on treatments available in Hong Kong) dehydration or renal dysfunction. ${ }^{23}$ The Food and Drug Administration has classified linaclotide as a pregnancy category $\mathrm{C}$ drug. ${ }^{29}$

\section{Statement 10: Stimulant laxatives should be} regarded as rescue therapy for chronic idiopathic constipation, not as first-line agents, and used only on an as-needed basis (less than daily). Regular chronic use of stimulant laxatives is discouraged. Long-term use of glycerine suppositories and/or water enemas is acceptable

Stimulant laxatives increase intestinal motility and intestinal secretion. Commonly used stimulant laxatives include Agiolax, senna (Senokot), and bisacodyl (Dulcolax). Frequent use of these agents may lead to long-term dependency or abuse, and therefore, general practitioners or specialists should counsel patients on limiting their use. ${ }^{30}$ The concern that stimulant laxatives may cause permanent damage to the autonomic nervous system of the colon has not been proven. ${ }^{15}$

Statement 11: Surgery should only be used as a last resort for slow-transit constipation or to treat identified disorders that require surgical correction. Exclusion of defaecatory disorder and whole gut slow transit problems is important

Defaecatory disorder commonly coexists with slow- or normal-transit constipation. ${ }^{31}$ This is a common cause that contributes to poor laxative treatment response. These patients must be properly assessed by gastroenterologists with expertise in management of functional bowel disorder before being recommended for surgery.

Surgery is generally not effective for management of refractory CIC and is associated with significant morbidity. ${ }^{10}$ Rare conditions like megacolon may be an indication for surgery. The proposed management algorithm for CIC is summarised in the Figure.

\section{Conclusions}

Chronic constipation is a common gastrointestinal disorder in patients presenting to primary care providers. These consensus statements give a general overview of diagnostic and treatment approaches to CIC appropriate for primary care physicians in Hong Kong.

Diagnosis of CIC is made using the revised Rome IV criteria, along with simple laboratory tests and physical examinations, which are important for excluding secondary causes, such as medications, electrolyte imbalances, structural abnormalities, and metabolic or pathological disorders. ${ }^{5,8}$ Patients presenting with alarming features should be referred to gastroenterologists or surgeons for appropriate further assessments. 
Dietary and lifestyle adjustments should be attempted first before initiating pharmacological treatments for CIC. Soluble fibre supplementation may improve stool frequency, but excessive use of bulking agents (especially insoluble fibre) may lead to bloating and faecal impaction. Among osmotic agents, PEG is more effective and better tolerated than lactulose. ${ }^{6,19}$

Linaclotide may be considered as second-line therapy for patients who have failed fibre and osmotic laxatives. ${ }^{6}$ It is the only prosecretory agent currently registered for use in Hong Kong. Linaclotide has been demonstrated to generate significant improvements of constipation symptoms in CIC compared with placebo, but diarrhoea is a significant concern, especially with the higher dose that is normally used $(290 \mu \mathrm{g})$. Lubiprostone, linaclotide, and plecanatide are all superior to placebo for treatment of CIC, but no head-to-head trials comparing these medications have been conducted thus far.

\section{Author contributions}

All authors contributed to the concept, acquisition of data, interpretation of data, drafting of the manuscript, and critical revision for important intellectual content. All authors had full access to the data, contributed to the study, approved the final version for publication, and take responsibility for its accuracy and integrity.

\section{Conflicts of interest}

All authors have disclosed no conflicts of interest.

\section{Funding/support}

English language editing and writing support, funded by an unrestricted educational grant from AstraZeneca Hong Kong Limited, was provided by Cassandra Thomson and Shirani Kanaganayagam of MIMS (Hong Kong) Limited.

\section{References}

1. Cheng C, Chan AO, Hui WM, Lam SK. Coping strategies, illness perception, anxiety and depression of patients with idiopathic constipation: a population-based study. Aliment Pharmacol Ther 2003;18:319-26.

2. Heaton KW, Radvan J, Cripps H, Mountford RA, Braddon FE, Hughes AO. Defecation frequency and timing, and stool form in the general population: a prospective study. Gut 1992;33:818-24.

3. Johanson JF, Kralstein J. Chronic constipation: a survey of the patient perspective. Aliment Pharmacol Ther 2007;25:599-608.

4. Rao SS, Meduri K. What is necessary to diagnose constipation. Best Pract Res Clin Gastroenterol 2011;25:127-40.

5. Lacy BE, Mearin F, Chang L, et al. Bowel disorders. Gastroenterology 2016;150:1393-407.

6. Tse $\mathrm{Y}$, Armstrong $\mathrm{D}$, Andrews $\mathrm{CN}$, et al. Treatment algorithm for chronic idiopathic constipation and constipation-predominant irritable bowel syndrome derived from a Canadian national survey and needs assessment on choices of therapeutic agents. Can J
Gastroenterol Hepatol 2017;2017:8612189.

7. Nehra V, Bruce BK, Rath-Harvey DM, Pemberton JH, Camilleri M. Psychological disorders in patients with evacuation disorders and constipation in a tertiary practice. Am J Gastroenterol 2000;95:1755-8.

8. Shin JE, Jung HK, Lee $\mathrm{TH}$, et al. Guidelines for the diagnosis and treatment of chronic functional constipation in Korea, 2015 revised edition. J Neurogastroenterol Motil 2016;22:383-411.

9. Lembo A, Camilleri M. Chronic constipation. N Engl J Med 2003;349:1360-8.

10. Sobrado CW, Neto IJ, Pinto RA, Sobrado LF, Nahas SC, Cecconello I. Diagnosis and treatment of constipation: a clinical update based on the Rome IV criteria. J Coloproctol 2018;38:137-44.

11. Power AM, Talley NJ, Ford AC. Association between constipation and colorectal cancer: systematic review and meta-analysis of observational studies. Am J Gastroenterol 2013;108:894-903.

12. Gwee KA, Bergmans P, Kim J, et al. Assessment of the Asian Neurogastroenterology and Motility Association chronic constipation criteria: An Asian multicenter crosssectional study. J Neurogastroenterol Motil 2017;23:26272.

13. Whitehead WE, Bharucha AE. Diagnosis and treatment of pelvic floor disorders: what's new and what to do. Gastroenterology 2010;138:1231-5.

14. Zhang R, Wang Z, Fei Y, et al. The difference in nutrient intakes between Chinese and Mediterranean, Japanese and American diets. Nutrients 2015;7:4661-88.

15. Müller-Lissner SA, Kamm MA, Scarpignato C, Wald A. Myths and misconceptions about chronic constipation. Am J Gastroenterol 2005;100;232-42.

16. Ford AC, Moayyedi P, Lacy BE, et al. American College of Gastroenterology monograph on the management of irritable bowel syndrome and chronic idiopathic constipation. Am J Gastroenterol 2014;109 Suppl 1:S2-26.

17. Wang X, Yin J. Complementary and alternative therapies for chronic constipation. Evid Based Complement Alternat Med 2015;2015:396396.

18. Zhong LL, Cheng CW, Kun W, et al. Efficacy of MaZiRenWan, a Chinese herbal medicine, in patients with functional constipation in a randomized controlled trial. Clin Gastroenterol Hepatol 2018 Apr 12. Epub ahead of print.

19. Cheng CW, Bian ZX, Zhu LX, Wu JC, Sung JJ. Efficacy of a Chinese herbal proprietary medicine (Hemp Seed Pill) for functional constipation. Am J Gastroenterol 2011;106:1209.

20. Lee-Robichaud H, Thomas K, Morgan J, Nelson RL. Cochrane review: lactulose versus polyethylene glycol for chronic constipation. Evidence-Based Child Health 2011;6:824-64

21. Zheng S, Yao J. Expert consensus on the assessment and treatment of chronic constipation in the elderly. Aging Med 2018;1:8-17.

22. Abcar A, Hever A, Momi JS, Sim JJ. Acute phosphate nephropathy. Perm J 2009;13:48-50.

23. Lembo AJ, Schneier HA, Shiff SJ, et al. Two randomized trials of linaclotide for chronic constipation. N Engl J Med 2011;365:527-36.

24. McRorie JW, Daggy BP, Morel JG, Diersing PS, Miner PB, Robinson M. Psyllium is superior to docusate sodium for 
treatment of chronic constipation. Aliment Pharmacol Ther 1998;12:491-7.

25. Jiang $\mathrm{C}$, Xu Q, Wen X, Sun H. Current developments in pharmacological therapeutics for chronic constipation. Acta Pharm Sin B 2015;5:300-9.

26. Ford AC, Suares NC. Effect of laxatives and pharmacological therapies in chronic idiopathic constipation: systematic review and meta-analysis. Gut 2011;60:209-18.

27. Lacy BE, Schey R, Shiff SJ, et al. Linaclotide in chronic idiopathic constipation patients with moderate to severe abdominal bloating: a randomized, controlled trial. PLoS One 2015;10:e0134349.

28. Miner PB Jr, Koltun WD, Wiener GJ, et al. A randomized phase III clinical trial of plecanatide, a uroguanylin analog, in patients with chronic idiopathic constipation. Am J Gastroenterol 2017;112:613-21.

29. Linzess (linaclotide capsules): highlights of prescribing information. Available from: https://www.accessdata. fda.gov/drugsatfda_docs/label/2012/202811s000lbl.pdf. Accessed 19 Mar 2019.

30. Thomas RH, Allmond K. Linaclotide (Linzess) for irritable bowel syndrome with constipation and for chronic idiopathic constipation. P T 2013;38:154-60.

31. Roerig JL, Steffen KJ, Mitchell JE, Zunker C. Laxative abuse: epidemiology, diagnosis and management. Drugs 2010;70:1487-503. 